\title{
Effectiveness of Online Teaching and Learning of Wood Science and Technology Courses during the COVID-19 Pandemic: Early Evidences from a Survey of Malaysian Universities
}

Jegatheswaran Ratnasingam, ${ }^{\mathrm{a}, *}$ Natkuncaran Jegathesan, ${ }^{\mathrm{b}}$ Hazirah Ab Latib, ${ }^{\mathrm{a}}$ Lee Yan Yi, ${ }^{a}$ Manohar Mariapan, ${ }^{a}$ Florin Ioras, ${ }^{\mathrm{c}}$ and Amir Affan Abdul Azim ${ }^{\mathrm{a}}$

Wood Science and Technology (WST) courses have been traditionally taught face-to-face in most of the universities worldwide, but the global COVID-19 pandemic has disrupted classroom lessons, replacing them with online teaching and learning methods. To assess the effectiveness of these online methods, a survey of students and academics were carried out in several Malaysian universities offering the WST programs. The survey revealed that students were mostly challenged by the problems related to access to internet, computer hardware, and lack of communication. Further, the student-centered learning method was preferred, while non-technical courses were the most suited for online teaching and learning. In contrast, academics appear to prefer prerecorded lectures and recorded videos as the most common method for teaching online, while continuous assessment of the student's progress found limited application. The results found that to enhance the effectiveness of teaching and learning online of WST courses, factors such as connectivity, student's preparedness, content design, pedagogical approach, peer communication, and the teacher's presence, must be taken into consideration and improved.

Keywords: Online learning; Wood science and technology; Assessment; Student-centered learning; Connectivity; COVID-19; Distance learning;

Contact information: a: Department of Natural Resources Industry, Faculty of Forestry and Environment, University Putra Malaysia, 43400 UPM, Serdang, Selangor, Malaysia; b: Faculty of Business, University of Wollongong, New South Wales 2522, Australia; c: Enterprise and Innovation Center, Buckinghamshire New University, Queen Alexandra Road, High Wycombe, HP11 2JZ Buckinghamhire, England;

*Corresponding author: jswaran1965@gmail.com

\section{INTRODUCTION}

In this digital age, teaching and learning are increasingly becoming dependent on computer and information technology (ICT), which also serves as a learning tool to promote efficient learning. Digital technologies can be used to connect and support learners working together, inevitably facilitating knowledge construction, collaboration, and reflection (Appana 2008). The prevailing connectivity achieved through the World-WideWeb (WWW), where learners as well as knowledge creators connect with other participants with similar interests who can give feedback, is indeed the foundation of the digital age. Further, the digital age also allows for sharing and critiquing of knowledge as it is developed, thus making it possible to find the information in seconds. Unfortunately, this has resulted in lower importance accorded to remembering figures and facts, which are often regarded as the hallmark of the traditional learning method (Jones et al. 2008). 
It is apparent that the tradition of face-to-face teaching and learning is slowly being replaced with E-learning (or also known as online teaching and learning), as its flexibility allows students to engage in studying without conflict with family or work. In the developed world, adult and matured students share active E-learning culture and are positively motivated and prefer obtaining knowledge and skills at convenient times. In contrast, it has been reported that E-learning with supplementary tailored explanations can enrich the conventional face-to-face education lessons (Kim 2006).

Since the emergence of the COVID-19 global pandemic in early 2020, teaching and learning in schools, colleges, and universities have been disrupted throughout the world, and the E-learning system has been tested to the fullest, as face-to-face education was halted in many countries (Mohan et al. 2020). Whether E-learning can provide systematic, sustained, and demanding teaching and learning experiences to students, young and old, in various fields of interdisciplinary study and programs, remains to be seen. In fact, the question of whether E-learning promotes life-long learning to increase the students' knowledge ability, education, and knowing is also being tested during this period.

\section{E-Learning and Its Benefits}

The development of E-learning has come a long way since the middle of the last century (MacDonald and Thompson 2005). It first started via correspondence, later using radio, television, and CD-ROM. With the use of CD-ROMs, computer-based E-learning started, which evolved into online and real-time lectures, as seen today. In fact, E-learning has transformed education into learning at any time, at any place, and at any pace (Menchaca and Bekele 2008). It must be recognized that E-learning has transformed education for the masses, and consequently it has contributed to improving the literacy rate among the world population.

Other advantages of E-learning are: (1) economic benefits (i.e., lower overhead cost), (2) administration of various courses is eased, (3) learning and teaching comfort is improved through the use of e-mails, message boards, telegram, WhatsApp, Zoom Video Communications, Cisco Webex, etc., (4) students' management is eased, (5) interdisciplinary courses can be facilitated, (6) sharing courses and networking for students is markedly improved, (7) it improves reliability, safety, and continuous access of courses, (8) it provides a service for detecting plagiarism and hence improves quality assurance, and (9) it allows the students to keep track of their learning pace and progress report (MacDonald and Thompson 2005).

Generally, E-learning is in a way more challenging than classroom learning, as personal contact and immediate reactions are not part of the learning and teaching processes, as they are in face-to face settings. Ma (2006) argued that replacing conventional face-to-face teaching and learning with E-learning methods is unlikely to be effective, as the lack of good information and communication technology (ICT) infrastructure and limited access to multidisciplinary professionals poses huge challenges in many developing countries. Within the Association of Southeast Asian Nations (ASEAN) region, adopting a blended system that combines the asynchronous and synchronous course elements (i.e., face-to-face and online phases) has however provided encouraging results. According to Ratnasingam (2017), the preference for asynchronous E-learning method in the ASEAN region appears to be overwhelmingly well received, as it provides the students with both personal face-to-face lessons as well as expanded perspectives to the subject matter delivered through online lessons from elsewhere 


\section{E-learning in Wood Science and Technology Education}

Lewark and Längin (2007) were the pioneer researchers in E-learning in forestry and wood science education. They argued that E-learning would expand the opportunities of offering wood science and technology courses to a wider global audience, beyond the traditional university or college resident population.

The Virtual European Forestry University, VIEFOR, seems to have been the earliest initiative from the side of SILVA Network universities in Northern Europe (Tahvanainen 2004). Although it was a success in the initial years of inception, in the later years it was only used for support of on-campus teaching at the University of Eastern Finland (formerly University of Joensuu) in the frame of the study program Master of European Forestry.

Later, a much larger E-learning center was established at the University of Natural Resources and Applied Life Sciences (BOKU) in Vienna, which is focused on use for on campus teaching as well, now using the shareware of MOODLE.

This was followed by the efforts by the Faculty of Forest and Environmental Sciences of the University of Freiburg in Germany in establishing the E-learning platform known as "CampusOnline".

Other notable E-learning education for wood science and technology programs include the Natural Resources Distance Learning Courses (NRDLC) with 10 US American universities, European-African Network to improve HEIs in Agriculture and Forestry based on new labour market needs (AFOLM) in Africa and World-wide E-Learning Academy for Natural Resources, Forestry and Wood Science (WELAN), which are in different stages of realization (Langin et al. 2004; Che and Lewark 2011). It seems to be too early to say whether these E-learning initiatives will be successful in the long-run, as reports on the success of E-learning for wood science and technology programs have not been extensively researched and documented. Perhaps, the uncertain future of many Elearning initiatives stems from the fact that E-learning initiatives are usually not anchored in the curricula in many universities throughout the world (Lewark and El-Lakany 2010).

Within the South East Asian region, one of the most notable efforts in E-learning education in the forestry sector is a series of online notes, videos, and other materials made available on the website of the Asia Pacific Forestry Education Coordination Mechanism (APFECM), which is financially supported by the Beijing Forestry University in China and the University of British Columbia in Canada (Ratnasingam 2017). Several Sustainable Forest Management (SFM) modules are available online that can be accessed through their website. Despite the free access to such modules, it has been reported to that the number of visitors as well as the downloads of the modules have been limited, suggesting the lack of awareness of the availability of such modules or its limited application (Ratnasingam 2017).

The major hindrance to E-learning in many developing countries are the limitations of infrastructure, including the lack of hardware, insufficient bandwidth, and the excessive cost of internet (Ma 2006; Olszewska 2020). In many universities there seems to be little incentive provided on the level of the faculty. There is not much demand anchored in study programs, and only a few professors have the competence and the drive to do it. Most professors in wood science and technology programs do have a high workload in teaching and other duties. They have their obligations in the traditional or many new study programs. Further, not all courses existing in the WST program can be taught and learnt through E-learning, but more from the experiences. In this context, the question of to what extent E-learning would be successful and effective for the wood science and technology program warrants immediate analysis. 
Similar to engineering curriculum, the Wood Science and Technology (WST) curriculum has a high content laboratory practices, especially among the core courses. Ratnasingam (2017) has shown that in the existing WST programs in Malaysia the handson practical and laboratory sessions account for $63 \%$ of the total contact time for the 3 credit core courses, which renders it difficult to be taught on-line. Further, without the hands-on practical sessions, the students will lack the necessary exposure and "show and tell" sessions to enable them to better comprehend the theoretical concepts. Inevitably, it will produce graduates who are ill-equipped for their future employment. Another impact of the lack of hands-on practical sessions is the disruption in teaching and learning of advanced courses, which has pre-requisite courses of the lower levels.

Perhaps the application of up to date teaching and learning tools, such as virtual reality (VR), augmented reality (AR), 3D printing, etc. which may be available in the future classroom setting, might be the way to go with the more technically inclined courses in the WST curriculum, but to support such applications and tools, high internet speed and bandwidth will be required.

From an industrial perspective, it is equally important to also evaluate what new skills are expected of WST graduates, especially now that many potential employers are seriously weighing-in on options of adopting a higher degree of automation in the factory shop-floor, as well as a shift towards the incorporating more elements of Industry 4.0 (Quesad-Pineda et al. 2011). Therefore, it will be naive to assume that the present WST curriculum is sufficient to navigate through the uncertainties in the marketplace. Further, it may also be important to assess whether E-learning can fulfill the requirements and aspirations both of potential employers and future WST graduates.

The COVID-19 pandemic has raised noticeable challenges for the higher education sector in Malaysia, where almost all wood science and technology programs are taught through E-learning as opposed to face-to-face lessons. In this context, a study was undertaken to evaluate the effectiveness of WST courses conducted through E-learning among Malaysian students enrolled in WST programs, as well the academics or instructors of these programs throughout the country. The outcomes of this study will contribute towards enhancing the overall teaching and learning during the 'new normal' era, post COVID-19 pandemic era, where E-learning could be the norm rather than the exception. Further, this study will also shed some light into the viability and effectiveness of using Elearning for WST programs.

\section{METHODOLOGY}

Generally, there is such diversity in E-learning and face-to-face learning practices that it is difficult, and perhaps a little dangerous, to make sharp contrasts between them. Each is quite heterogeneous in their own right. Nevertheless, E-learning implies a certain pedagogical content knowledge (PCK), mainly related to designing and organizing for better learning experiences and creating distinctive learning environments, with the help of digital technologies (Reimers and Schleicher 2020).

During the COVID-19 pandemic and the ensuing series of lockdowns, all WST programs at public universities in Malaysia were conducted online. Therefore, to boost the reliability of this study, the survey was carried out among 600 students from Universiti Putra Malaysia (UPM), Universiti Sains Malaysia (USM), Universiti Malaysia Sabah (UMS), and Universiti Teknologi MARA (UiTM), where WST and related programs were being offered. $53 \%$ of the student respondents were female, while the balance $47 \%$ were 
male students. The student respondents were in either the $3^{\text {rd }}$ or $4^{\text {th }}$ year of undergraduate program, with an average age 22 to 24 years old. These students were contacted randomly with the assistance of their respective course leaders. Further, a total of 40 academic staff or instructors of various courses from these universities were also invited to participate in a parallel survey conducted for academics and instructors. The academics who participated in this survey had at least 10 years or more of teaching experience in the WST program, and were between 35 and 50 years old. Male academics made up $85 \%$ of the respondents, while the female academics made up the balance $15 \%$ of the respondents.

An invitation email was sent to the targeted respondents, both students and academics, to participate in the survey conducted via Google Forms. A link to the questionnaire was also posted on to the website of the team leader of this study, throughout the study period. The questionnaire was sent out to seek a straight-forward response from the respondents, without much ambiguity or deliberation, based on their experience of online education. At the end of an 8-week period, a response rate of $99 \%$ was achieved, clearly indicating that the probability of error and non-response bias were small (Fowler 2002; Israel 2009). The questionnaire was designed after a series of discussions with fellow academics and student groups in these universities, after which, a pre-test was carried out to improve the final questionnaire before the actual survey commenced. The survey questionnaire was based on a multiple response format. Respondents were asked to check a specific number of items from a total number of items. This type of response format allowed the extraction of the necessary information required to fulfill the objectives of the study, while making the procedure efficient and straightforward (Santos 2000; OECD 2005).

The questionnaire for students had four parts. Part I required the students to rank the top eight challenges faced during on-line learning during the COVID-19 pandemic. Part II required the students to identify the four most preferred online methods of teaching and also indicate the percentage of courses that they were satisfied with the online teaching methods used. Part III required the students to rank the courses by their ease of learning through online. Part IV required the students to identify the most important elements from a list of ten that would improve their E-learning experience.

The questionnaire for the academic or instructors also had four parts. Part I required the academics or instructors to identify the five most common methods adopted for on-line teaching of their courses. Part II required the academics or instructors asked to select the most preferred on-line assessment method for their respective course. Part III required the academic or instructors to identify the courses that could be taught through on-line modes, based on their degree of effectiveness. Part IV required the academics or instructors to identify the five most important element that they perceived would contribute most towards effective on-line teaching.

The compiled data of responses were analyzed, and the averages were calculated. The top factors identified or selected from each part of the survey, both from the students and academics perspectives, were also presented graphically. The student's T-test was used to ascertain the significance between the students' and academics' responses from the parallel surveys conducted, which was set at $\mathrm{P}<0.05$. The $\mathrm{P}$-value is the probability that the results from the data occurred by chance and reflects the probability of finding the results to show no significant differences between the factors tested (i.e., null hypothesis). It is calculated using the sampling distribution of the test statistic under the null hypothesis, the sample data, and the type of test being done. This was carried out using the Excel Spreadsheet of Microsoft Windows Professional Version 10 (Redmond, WA, USA). 


\section{RESULTS AND DISCUSSION}

\section{Part I: Students Perspectives Towards Online Learning}

It is apparent that students in WST programs in the Malaysian universities were faced primarily with an infrastructure problem, especially those related to access to internet and WIFI. Other hindrances included poorly designed content of courses, lack of peer interaction, and the overwhelming subject-matter or teacher-centered approach (Table 1). This finding is also supported by a report by the Malaysian Technology Development Corporation (MTDC) (2020), who showed that the access to the internet and limited computer/hardware were often cited as the main challenges faced by students residing in the rural areas. Likewise, without peer interaction, which is a weakness of the online learning, students feel isolated when working alone, and this thereby scuttles their learning experience (Olszewska 2020).

Conception of space and social presence becomes salient when online modalities are adopted. Technology has a way of altering time and space, metaphorically compressing them. In face-to-face classrooms, academics and students are physically and temporally co-present (synchronous). In contrast, in online learning the students are usually not only physically distant, but also temporally distant (asynchronous through the use of text messaging, pre-recorded video, etc.). Inevitably, it is important to ensure that the students' learning experience is not weakened through the non-presence of the academic or instructor and also limited communication (Chang et al. 2017; Page 2020).

The fact that the COVID-19 pandemic caught everyone by surprise also reveals the glaring weaknesses in courses that have been traditionally taught face-to-face, but had to abruptly be adopted for online delivery.

Table 1. Challenges to Online Learning

\begin{tabular}{|l|c|}
\hline Constraints & Weightage \\
\hline Access to internet & $24 \%$ \\
\hline Lack of bandwidth & $19 \%$ \\
\hline Poorly designed content & $13 \%$ \\
\hline Lack of peer interaction & $12 \%$ \\
\hline Poorly mediated communication & $11 \%$ \\
\hline Teacher/subject matter centered & $8 \%$ \\
\hline Unrealistic expectations & $6 \%$ \\
\hline Unclear assessment & $4 \%$ \\
\hline Reduced flexibility & $3 \%$ \\
\hline
\end{tabular}

As expected, Fig. 1 reveals that most of the students preferred online learning delivered through flexible student-centered learning, which accommodates the diverse capability of the students enrolled in the program to cope with online education. Recorded lectures and live lectures, which were inclined towards the subject-matter centered were not well received by the students, similar to those highlighted in the report by Reimers $e t$ al. (2020).

Figure 2 shows that the ease of learning online courses in WST programs would decrease in the order of general studies $>$ management $>$ marketing $>$ finance $>$ ergonomics $>$ process technologies $>$ products manufacturing $>$ basic wood properties. Hence, technicaloriented courses that require a high degree of analytical and psychomotor skills could not be effectively delivered online (Quesada-Pineda et al. 2011). This point further reinforces the fact the WST courses with their high hands-on practical and laboratory sessions could not be implemented effectively through the on-line mode. The students also highlighted the fact that 
most of the courses in WST programs, being technical, require intense discussion and peer communication, which is limited in online learning modes and therefore, is ineffective.

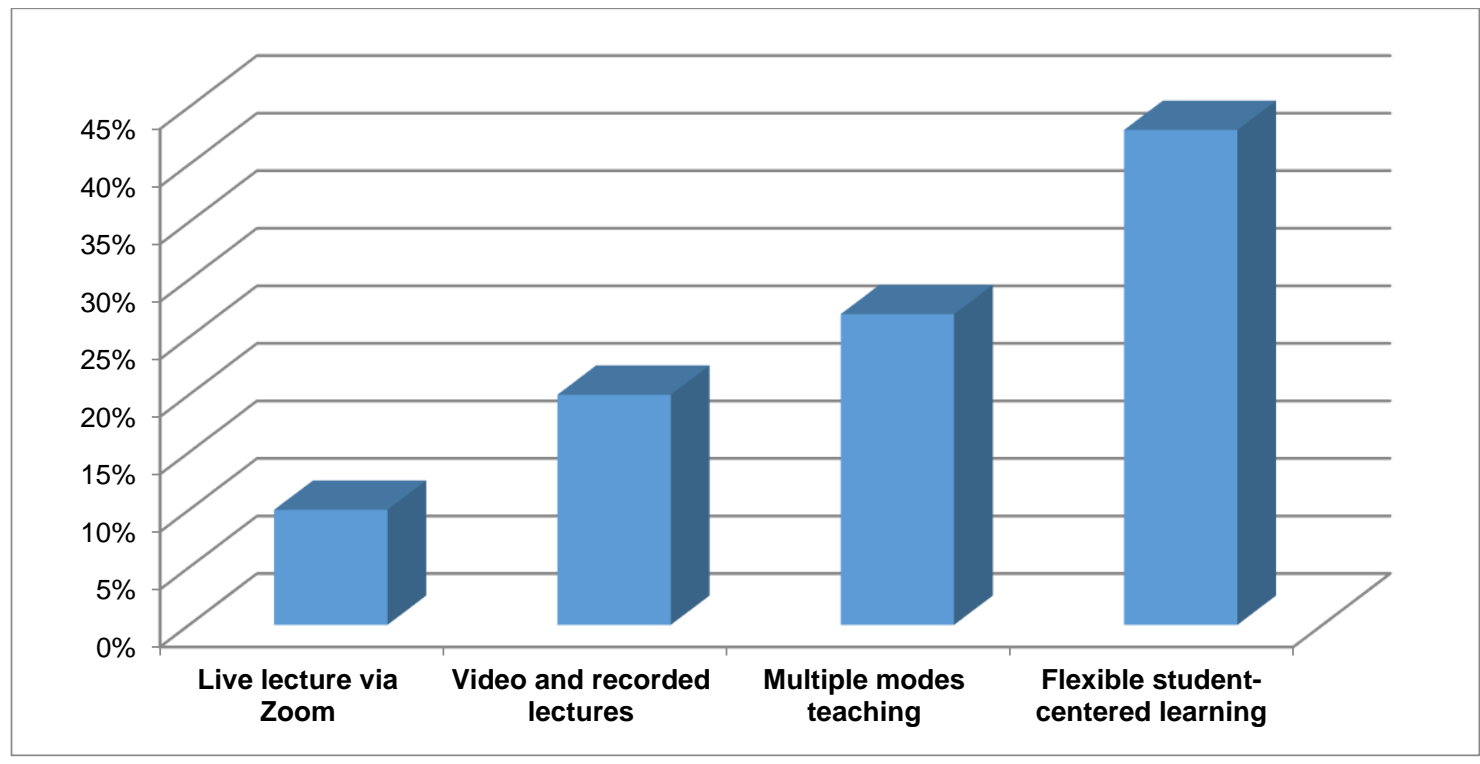

Fig. 1. Preferred online learning methods

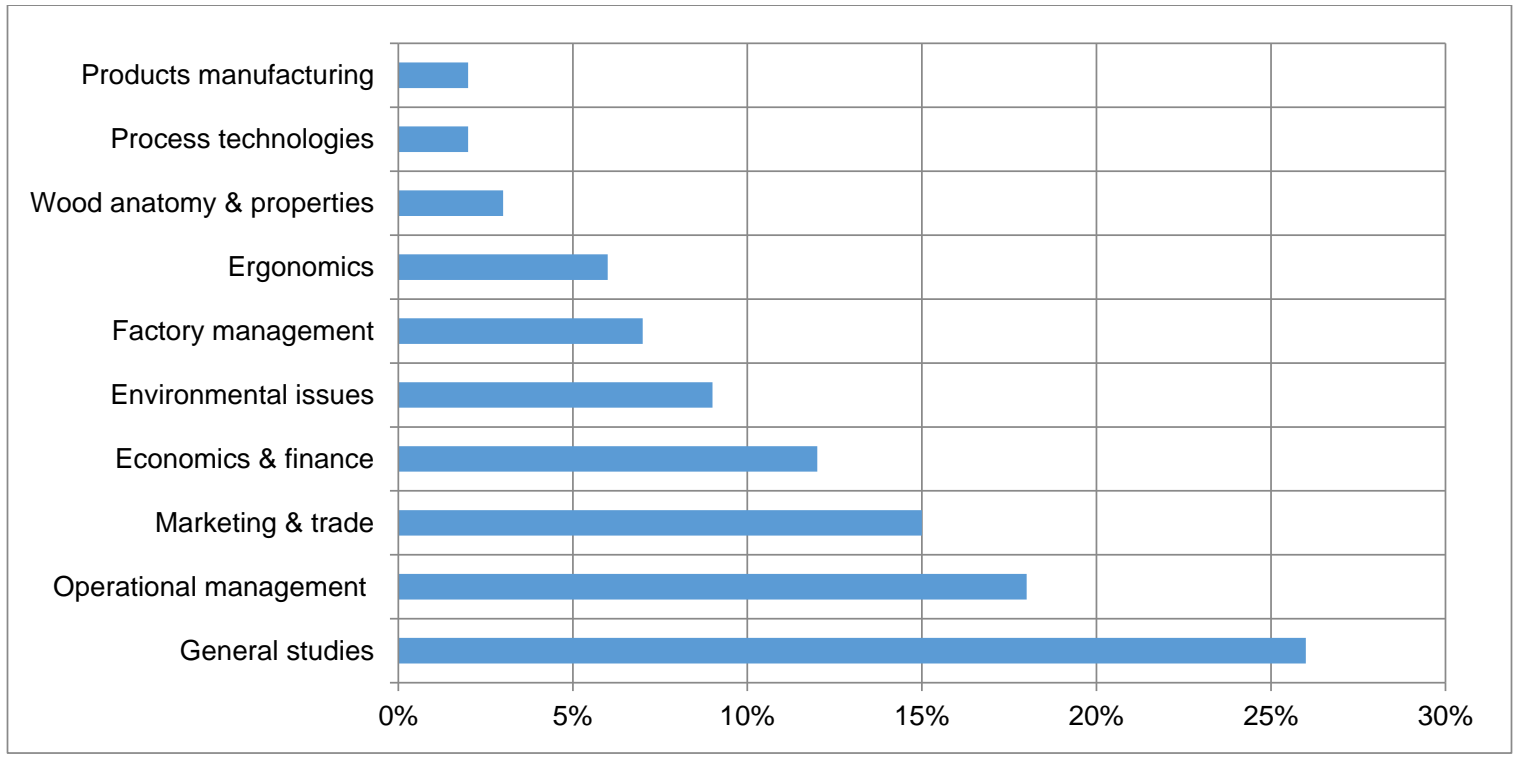

Fig. 2. Ease of using online learning for different courses in WST program

Figure 3 reflects that the students perceived the learning design or course delivery mode and the content design of the course, as the two main factors that would contribute towards effective online learning (Rosenberg 2001). Other factors, such as peer collaboration, learning at their own pace (i.e., autonomy), student's preparation for online learning, and communication, were also considered important for improving the effectiveness of online learning. Given the fact that connectivity and bandwidth limitations exist in the country, the course delivery mode is very important in ensuring successful online education. Asynchronous modes, which allow students to follow recorded lectures at their flexibility, while also allowing them time to work on assignments and returning them within the next days, are highly desirable. 

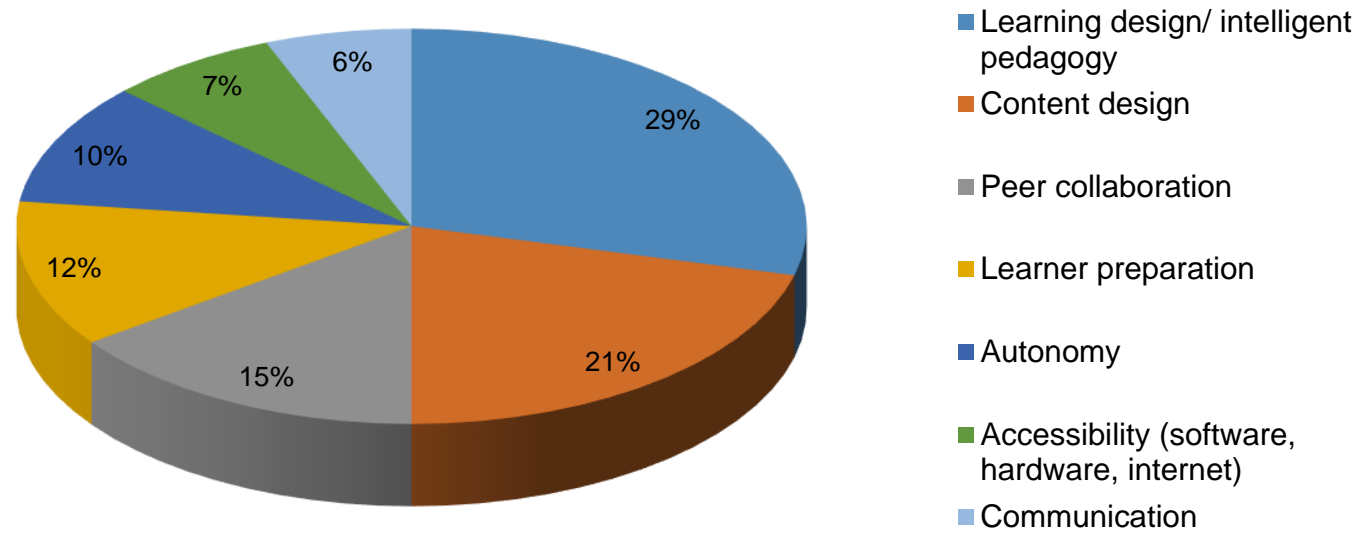

Fig. 3. Important factors that would enhance the effectiveness of online learning

This study reveals that design of online courses must have a strong student-centered approach. The role of the academic or instructor is merely to facilitate and support the student to develop competencies. In contrast, the student is responsible for his/her pace of learning, which requires autonomy of learning. Online learning should therefore allow selfpaced learning and reflections. Additionally, the students must be extended an open line of communication with the academics or instructors as well as their peers, to allow flexible evidence-based learning. Further, the student's progress should also be monitored closely to ensure continuous assessment of the student is done, which is the most suitable method of assessment for online education (Seifert 2020).

\section{Part II: Instructors Perspectives towards Online Learning}

Among the academics or instructors surveyed, it was obvious that the application of different modalities of online teaching were applied in the different universities. Nevertheless, it appears that there was a strong inclination towards subject-matter or teacher-centered approaches, which underline the unpreparedness of many academics in WST programs to undertake online teaching (Table 2 ). This finding clearly highlighted the plight of the students, who in most instances, felt isolated and working alone, due to the limited communication available between the student-academic and student-student (Sousa et al. 2019).

Table 2. Most Common Methods Used for Online Teaching

\begin{tabular}{|l|c|}
\hline Method of Online Teaching & Application \\
\hline Subject matter centered learning & $25 \%$ \\
\hline Online notes on learning management system (LMS) & $20 \%$ \\
\hline Recorded lectures and video & $17 \%$ \\
\hline Video conferencing/online live lectures & $15 \%$ \\
\hline $\begin{array}{l}\text { Mixed modalities (online discussion and class assignment via Zoom/Google } \\
\text { Team) }\end{array}$ & $13 \%$ \\
\hline Student centered learning & $10 \%$ \\
\hline
\end{tabular}

It may also be implied that due to the abrupt change imposed on the teaching mode upon academics and instructors, many of them were ill-prepared for online teaching and could not improve their teaching material to be student-centered design. Hence, there appears to be a lack of thinking into what actually the students have to learn in these 
courses. Further, the academics or instructors must also not assume that what they design and specify will be followed $100 \%$ by the students, and this is acceptable as the students' engagement in the design and execution of learning tasks functions positively towards selfregulation (Zhou et al. 2020).

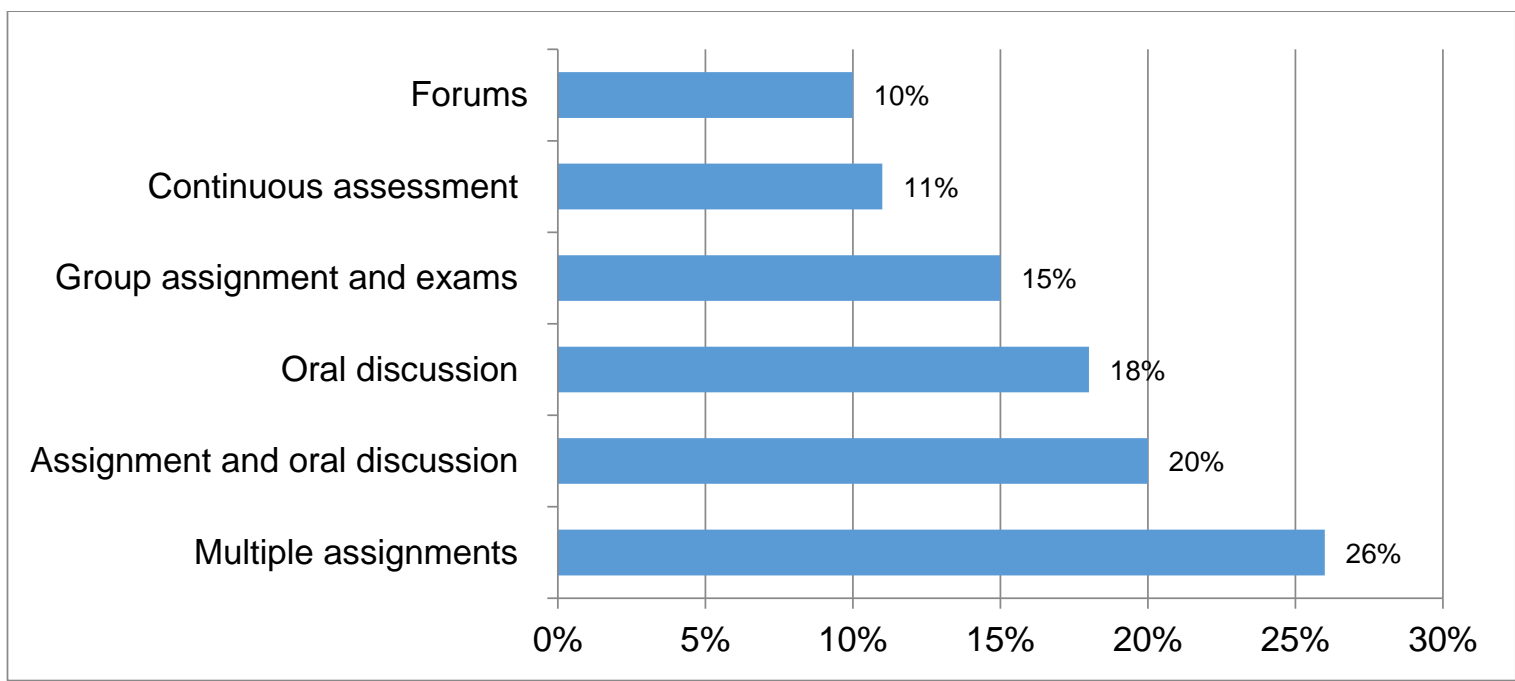

Fig. 4. Preferred assessment methods

The results from Fig. 4 clearly suggest that most academics would prefer to assess their students through multiple-assessments, rather than continuous assessment. Under such circumstances, it may be implied that the academics or instructors surveyed had a subject-matter approach to online teaching and hence, the limited flexibility in the mode of assessment of the student's progress. However, previous studies have suggested that continuous assessment would be the best option to assess students when adopting online education (Benigno and Trentin 2000; Seifert 2020).

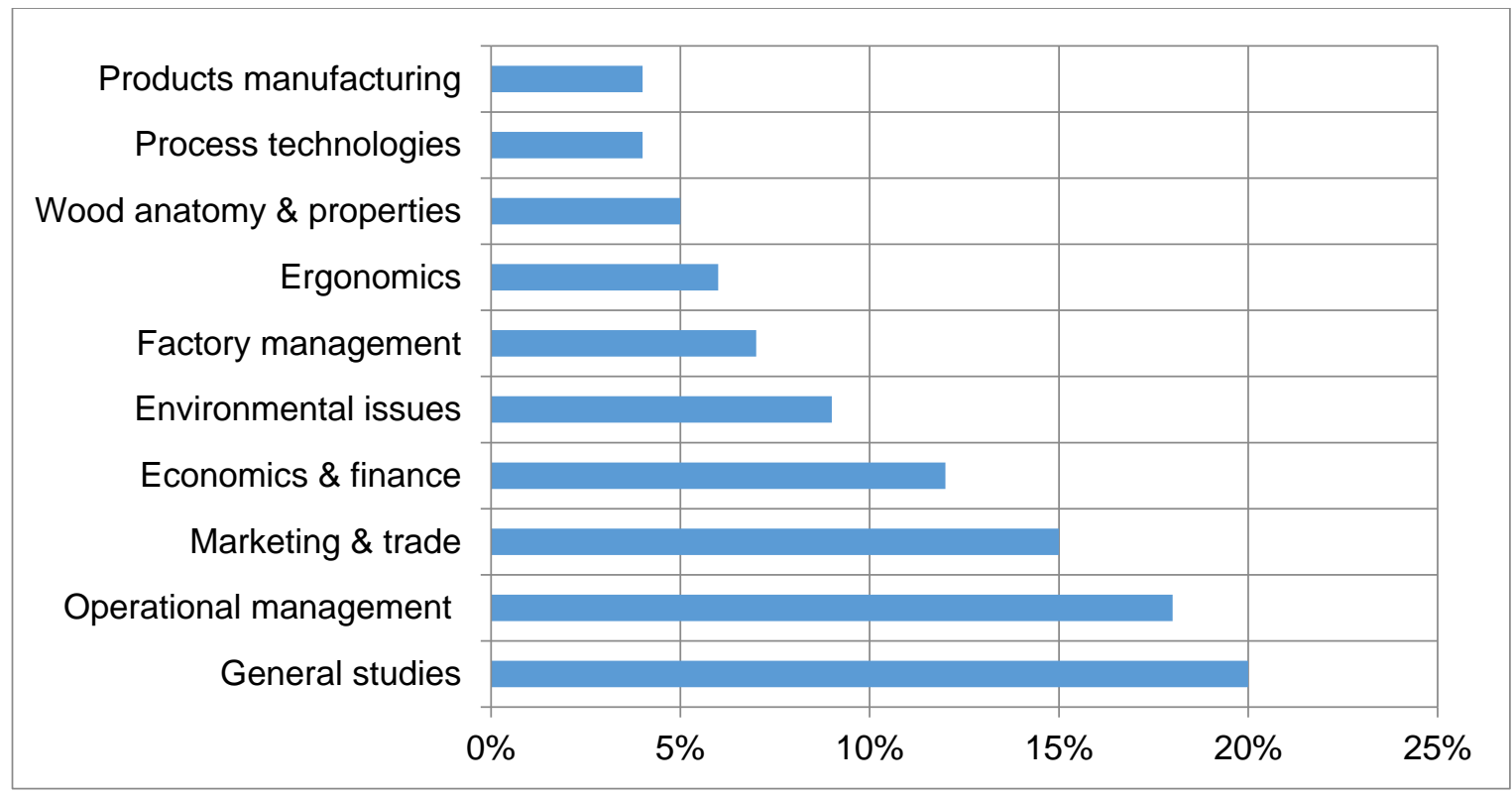

Fig. 5. Effectiveness of teaching courses through online 
Figure 5 shows that the ease of teaching online courses in WST programs would decrease in the order of general studies $>$ management $>$ marketing $>$ finance $>$ ergonomics $>$ process technologies $>$ products manufacturing $>$ basic wood properties. Hence, technicaloriented courses that require a high degree of analytical and psychomotor skills could not be effectively delivered online, a finding that is also parallel to the responses from the students' learning survey of the previous part. It must be emphasized that WST courses usually require a certain amount of hands-on work in laboratories, carrying out experiments and analysis, which is rather cumbersome to be done online (Badge et al. 2005; Olszewska 2020).

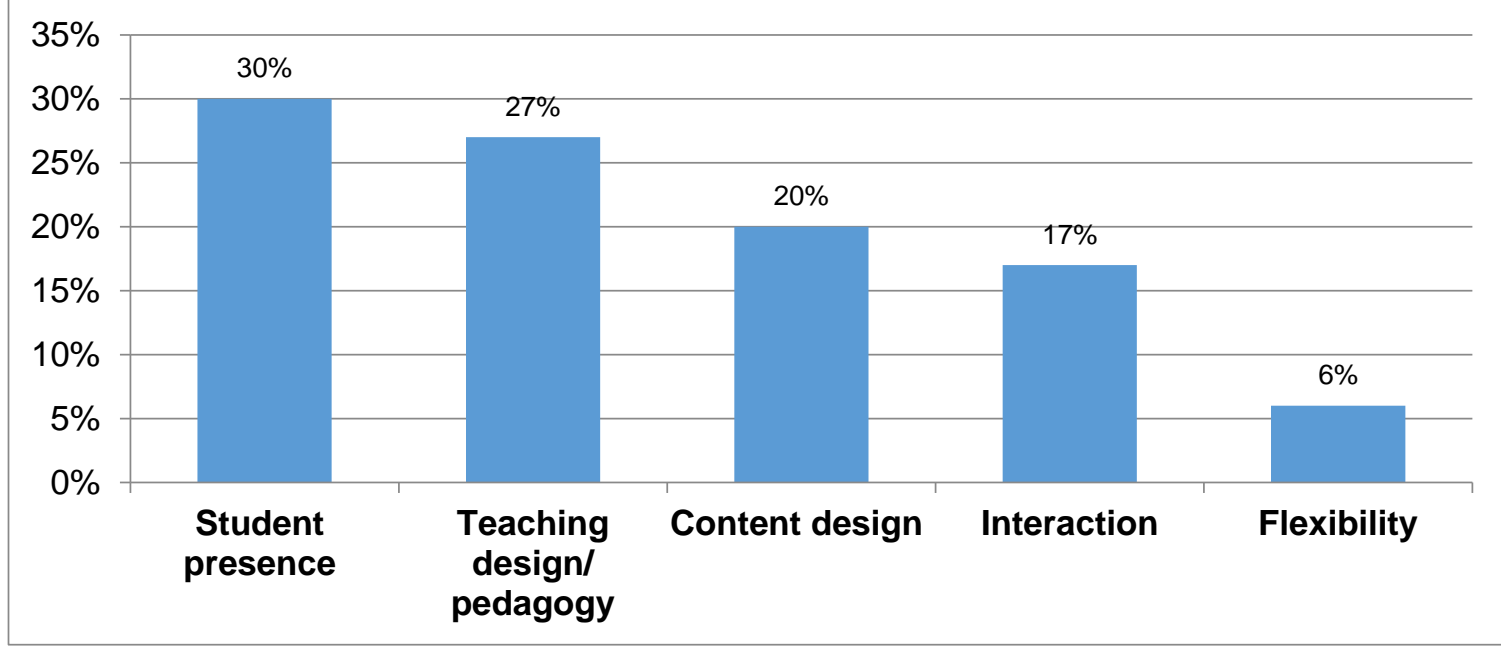

Fig. 6. Factors to improve effectiveness of online teaching

Figure 6 reveals that according to the academics, student's presence, teaching design or the pedagogical approach, and content design were the most important factors that affected the effectiveness of online teaching. Inevitably, it underlines the prevailing mind-set among Malaysia academics that the onus is on the student to learn, rather than the academic's responsibility to facilitate and grow the interest to learn among students (Benigno and Trentin 2000; Badge et al. 2005).

\section{IMPLICATIONS OF THIS STUDY}

The results of this study clearly reveal that the effectiveness of online education in Malaysia is compromised by the existing poor connectivity and limited accessibility to the internet. This is however an issue that must be tackled immediately by the relevant government agencies and network providers, to ensure that the necessary infrastructure is put in place to support effective online education. Further, students who are familiar with face-to-face education in a synchronous mode appear to be lost in the online environment due to limited communication with peers and academics. Further, the problem is further aggravated by the poorly designed content of on-line teaching material, which in many instances was improvised from the traditional subject-matter centered material. Under such circumstances, course delivery technology, such as recorded Microsoft Power Point presentations, forums, and chats that can be accessed by slow modem connections used by many students in the rural areas should be more extensively used. This will allow the students to assess asynchronous content and send their responses within the next days. Such course delivery technology cannot be discarded in the prevailing limited connectivity 
environment in the country. In contrast, the academics surveyed also revealed their lack of skills to conduct online teaching, both in terms of pedagogy as well as assessment, hence limiting it to the simple methods available to them but may not be the most suitable for the students. Similar to the findings of other reports about online teaching and learning (Olszewska 2020; Zhou et al. 2020), there is much work to be done, if online education is to be effective in the new normal in the post COVID-19 era. Both the students and academics or instructors must be accustomed to the various elements involved to ensure that online education is both effective and efficient. Despite this revelation, it must be emphasized that most highly successful teaching is done in a low-key manner by faculty members who care deeply about their students, and efforts are made to consistently ensure high academic-student-peer interactions. Such interaction will enable teaching and learning to proceed much more effectively and overcome many of shortcomings that may arise due to weak pedagogy or poor content design.

Nevertheless, online education of Wood Science and Technology courses could be transformed into being more captivating and interesting, if the Industry 4.0 technologies, such as virtual reality (VR), augmented reality (AR), 3D printing, and Internet of Things (IoT), are embedded into the existing online teaching and learning platforms, which will obviously improve the students learning experience, while at the same time improving the effectiveness of online teaching and learning. In fact, based on the anecdotal evidence available, it appears that the online teaching and learning of WST courses must incorporate many of the industry 4.0 tools to facilitate the appreciation and acquisition of technical know-how and psychomotor skills, which is usually delivered through face-to-face lessons and practical sessions (Olszewska 2020; Zhou et al. 2020). Given the prevailing limitation in connectivity and bandwidth, the use of such technologies in teaching and learning in the future classroom setting may be more amenable within the university campus, and it could be extended to the students who have access to high-speed internet in their homes. Against this background, it is important that present internet connectivity be considerably improved and the available bandwidth expanded by the relevant authorities and network providers to support other online tools and apps, if online education in Malaysia is to be improved and practiced more prevalently in the future.

\section{CONCLUSIONS}

1. Online learning of Wood Science and Technology (WST) courses by students were found to be challenged by the poor connectivity, access to internet, poor content design, limited interaction, improper assessment, and minimal teachers' presence.

2. Online teaching of WST courses by academics and instructors were compromised by the unpreparedness of students, lack of interaction with students, inappropriate pedagogical approach, and unrealistic expectations among students.

3. The study also revealed that non-technical courses, such as general studies, business, management, marketing, and finance, could be easily adopted to online teaching and learning as opposed to the technical courses.

4. Based on this study, it is apparent that students and academics have strong agreement in what would contribute towards effective online education for WST courses, which include factors such as content design, pedagogical approach, student's presence, teacher's presence, interaction, continuous assessment, and flexible and autonomous learning modes. 


\section{ACKNOWLEDGEMENTS}

The authors would like to thank colleagues at Universiti Teknologi Mara (UiTM), Universiti Sains Malaysia (USM), and Universiti Malaysia Sabah (UMS) for their support during the data collection and implementation of the survey. The financial support for conducting the survey was through the Universiti Putra Malaysia's PUTRA Grant Scheme No. 9649900.

\section{REFERENCES CITED}

Appana, S. (2008). "A review of benefits and limitations of online learning in the context of the student, the instructor and the tenured faculty," International Journal on Elearning 7(1), 5-22.

Badge, J. L., Cann, A. J., and Scott, J. (2005). "E-learning versus e-teaching: Seeing the pedagogic wood for the technological trees," Bioscience Education 5(1), 1-11. DOI: 10.3108/beej.2005.05000007

Benigno, V., and Trentin, G. (2000). "The evaluation of online courses," Journal of Computer Assisted Learning 16(3), 259-270. DOI: 10.1046/j.13652729.2000.00137.x

Chang, C. T., Hajiyev, J., and Su, C. R. (2017). 'Examining the students' behavioral intention to use e-learning in Azerbaijan? The general extended technology acceptance model for e-learning approach," Computers \& Education 111, 128-143. DOI: $10.1016 /$ j.compedu.2017.04.010

Che, V., and Lewark, S. (2011). "Strengthening learning and teaching in forestry and agriculture in African universities through E-learning and open education resources," in: Arbeitswissenschaftlicher Forschungsbericht, Freiburg: Institut für Forstbenutzung und Forstliche Arbeitswissenschaft Albert-Ludwigs-Universität Freiburg im Breisgau, Breisgau, Germany.

Fowler, F. (2002). "Designing questions to be good measures," in: Survey Research Methods, $4^{\text {th }}$ Ed., SAGE Publications, Thousand Oaks, CA, USA, pp. 86-113.

Israel, G. D. (2009). "Obtaining responses by mail or web: Response rates and data consequences," Survey Practice 2(5), 1-2. DOI: 10.29115/SP-2009-0021

Jones, C., Ferreday, D., and Hodgson, V. (2008). "Networked learning a relational approach: Weak and strong ties," Journal of Computer Assisted Learning 24(2), 90102. DOI: 10.1111/j.1365-2729.2007.00271.x

Kim, W. (2006). "Advances in web based learning," in: Proceedings International Conference and Web-based Learning (ICWL) 2006, New York, NY, USA.

Langin, D. W., Ackerman, P. A., and Lewark, S. (2004). "Internet-based learning in higher forestry education," UNASYLVA-216 55(1), 39-44.

Lewark, S., and El-Lakany, H. (2010). "Innovation through WELAN - the new worldwide e-learning academy for natural resources, forestry \& wood science," International Forestry Review 12(5), Article Number 443.

Lewark, S., and Längin, D. (2007). "Lehren und Lernen im forstwissenschaftlichen Studium über das Internet - Beispiele aus Arbeitswissenschaft und Genderlehre [Teaching and learning in forestry studies via the Internet- examples from ergonomics and gender theory," in: Neue Medien als strategische Schrittmacher an der Universität Freiburg [New Media as a Strategic Pacemaker at the University of Freiburg], G. Schneider, B. Couné, C. Gayer, E. Vogtle, and C. Weber (eds.), 
Universität Freiburg, Breisgau, Germany, pp. 149-160.

Ma, Z. (2006). Web-based Intelligence E-learning Systems, Information Science Pub., Hershey, PA, USA.

MacDonald, C. J., and Thompson, T. L. (2005). "Structure, content, delivery, service, and outcomes: Quality e-learning in higher education," International Review of Research in Open \& Distance Learning 6(2), 1-21. DOI: 10.19173/irrodl.v6i2.237

Malaysian Technology Development Corporation (MTDC) (2020). Status of Internet Access in Malaysia and Its Implication on E-Learning (Report. No. 4SP-1), Malaysian Technology Development Corporation, Putrajaya, Malaysia.

Menchaca, M., and Bekele, T. (2008). "Learner and instructor identified success factors in distance education," Distance Education 29(3), 231-252. DOI: 10.1080/01587910802395771

Mohan, G., McCoy, S., Carroll, E., Mihut, G., Lyons, S., and Mac Domhnaill, C. (2020). Learning for All? Second-level Education in Ireland During COVID-19 (Report No. 92), Economic and Social Research Institute (ESRI), Dublin, Ireland.

OECD (2005). Oslo Manual: Guidelines for Collecting and Interpreting Innovation Data ( $3^{\text {rd }}$ edition), OECD and Eurostat, Geneva, Switzerland. DOI: 10.1787/19900414

Olszewska, K. (2020). "The effectiveness of online learning in the era of the SARS-CoV2 pandemic on the example of students of Polish universities," World Scientific News 148, 108-121.

Page, A. (2020). "Using virtual teams to map digital new generation learning environments into tertiary online learning spaces," International Journal of Online Graduate Education 3(2), 1-24. DOI: 10.5281/zenodo.3934649

Quesada-Pineda, H. J., Conn, S., and Scarlett, L. S. (2011). “A survey of educational needs and online training perceptions in the wood products industry," Journal of Extension 49(1), Article Number 1RIB6.

Ratnasingam, J. (2017). Readiness to Distance and E-Learning in the Forestry Sector in the ASEAN Region (Report No. 4-2017), International Furniture Research Group (IFRG), Singapore.

Reimers, F. M., and Schleicher, A. (2020). "A framework to guide an education response to the COVID-19 Pandemic of 2020," OECD, (https://oecd.dambroadcast.com/pm_7379_126_126988-t63lxosohs.pdf), Accessed 14 April 2020.

Reimers, F., Schleicher, A., Saavedra, J., and Tuominen, S. (2020). "Supporting the continuation of teaching and learning during the COVID-19 Pandemic," OECD, (https://globaled.gse.harvard.edu/files/geii/files/supporting-the-continuation-ofteaching-and-learning-during-the-covid-19-pandemic.pdf), Accessed 14 April 2020.

Rosenberg, M. J. (2001). E-learning: Strategies for Delivering Knowledge in the Digital Age, McGraw-Hill, New York, NY, USA.

Santos, J. A. (2000). "Getting the most out of multiple response questions," Journal of Extension 38(3), 1-4.

Seifert, T. (2020). "Student assessment in online learning: Challenges and effective practices during COVID-19," in: Proceedings EdMedia+ Innovate Learning, Waynesville, NC, USA, pp. 106-108.

Sousa, M. J., Carmo, M., Gonçalves, A. C., Cruz, R., and Martins, J. M. (2019). "Creating knowledge and entrepreneurial capacity for higher education students with digital education methodologies: Differences in the perceptions of students and 
entrepreneurs," Journal of Business Research 94, 227-240. DOI:

10.1016/j.jbusres.2018.02.005

Tahvanainen, L. (2004). "Towards virtual European forestry faculty - A preliminary survey study," in: Proceedings of the Silva European Conferences, Warsaw, Poland, pp. 19-30.

Zhou, L., Wu, S., Zhou, M., and Li, F. (2020). 'School's out, but class' on', the largest online education in the world today: Taking China's practical exploration during the COVID-19 epidemic prevention and control as an example," Best Evidence of Chinese Education 4(2), 501-519. DOI: 10.15354/bece.20.ar023

Article submitted: September 19, 2020; Peer review completed: November 8, 2020;

Revised version received and accepted: November 17, 2020; Published: November 20, 2020.

DOI: $10.15376 /$ biores.16.1.403-416 